\title{
Geochemical features and organic origin of deep natural gas in the Sinian-Cambrian of central Sichuan paleo-uplift, Sichuan Basin, SW China
}

\author{
Wei Guoqi ${ }^{1,2}$, Xie Zengye ${ }^{1,2}$, Song Jiarong ${ }^{3}$
}

1. Langfang Branch of PetroChina Research Institute of Petroleum Exploration \& Development, Langfang 065007, China;

2. Key Laboratory of Gas Reservoir Formation and Development, CNPC, Langfang 065007, China;

3. PetroChina Southwest Oil and Gas Field Company, Chengdu 610000, China

\begin{abstract}
Based on the new drilling data and field outcrop data of the Gaoshiti-Moxi area, the geochemical characteristics of the Sinian-Cambrian natural gas are studied and analyzed, including gas composition, isotope, light hydrocarbon, kerogen carbon isotope and reservoir bitumen biomarkers etc. The results show that: (1) The natural gases of the Sinian Dengying Formation and Cambrian Longwangmiao Formation, mainly composed of hydrocarbon gas, are typical dry gas. However, the natural gas of the Dengying Formation is characterized by higher dry coefficient, lower content of hydrocarbon gas and higher content of non-hydrocarbon gas. The main differences in non-hydrocarbon gases are the contents of $\mathrm{N}_{2}, \mathrm{CO}_{2}, \mathrm{H}_{2} \mathrm{~S}$ and $\mathrm{He}$, the small composition differences between the natural gas of Dengying Formation and that of Longwangmiao Formation are mainly caused by maturity differences of source rocks and H2S generated by reaction between sulfide mineral and hydrocarbons. (2) There are obvious differences in $\delta^{13} \mathrm{C}_{2}$ between the natural gases in Dengying Formation and Longwangmiao Formation, showing different parent materials of them. (3) There are large differences in $\delta^{2} \mathrm{H}$ between the natural gases of Dengying Formation and Longwangmiao Formation, showing the different water salinities of their source rock depositional environment. (4)The average kerogen carbon isotope values of the Lower Cambrian shale, Dengying Formation mudstone, Doushantuo Formation mudstone and Dengying Formation carbonates are $32.8 \%$, 31.9\%o, 30.7\%o and 27.8\%o respectively. (5) The ratio of 4-methyl dibenzothiophene to 1-methyl dibenzothiophene of Dengying Formation bitumen is between that of Qiongzhusi Formation and Dengying Formation source rocks. It is believed that the Sinian-Cambrian natural gas in the Gaoshiti-Moxi area is mainly oil cracking gas, the Sinian natural gases come from the Sinian and Cambrian source rocks, and the Cambrian natural gases mainly come from Cambrian source rock.
\end{abstract}

Key words: natural gas; geochemical feature; Organic origin; Sinian-Cambrian; central Sichuan paleo-uplift; Sichuan Basin 